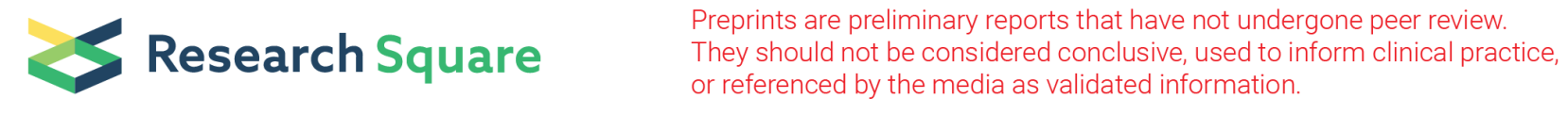

\title{
Spatial-temporal Distribution and Demography of Knowlesi Malaria in Peninsular Malaysia, 2011 to 2018
}

\author{
Wei Kit Phang \\ University of Malaya Faculty of Medicine \\ Mohd Hafizi bin Abdul Hamid \\ Ministry of Health Malaysia \\ Jenarun Jelip \\ Ministry of Health Malaysia \\ Rose Nani binti Mudin \\ Ministry of Health Malaysia \\ Ting-Wu Chuang ( $\nabla$ chtingwu@tmu.edu.tw ) \\ Taipei Medical University \\ Yee Ling Lau \\ University of Malaya Faculty of Medicine \\ Mun Yik Fong \\ University of Malaya Faculty of Medicine
}

Research

Keywords:

Posted Date: June 12th, 2020

DOI: https://doi.org/10.21203/rs.3.rs-34666/v1

License: (c) (i) This work is licensed under a Creative Commons Attribution 4.0 International License. Read Full License 


\section{Abstract}

Background: The life-threatening zoonotic malaria caused by Plasmodium knowlesi is on the rise in Malaysia; however, previous studies mainly focus on the transmission in Malaysian Borneo. This study aims to describe the basic epidemiological characteristics of P. knowlesi infection and identify spatial clustering of knowlesi malaria in Peninsular Malaysia. Methods : The spatial distribution of P. knowlesi monoinfection incidence was mapped across Peninsular Malaysia using Geographic Information System (GIS) approach. Demographic characteristics of the infection was investigated. Global and Local Moran's I were used to analyze spatial autocorrelation and define clustering of knowlesi malaria incidence. Results : Gua Musang and Lipis maintained the highest incidence rate (IR) as compared to other districts. Spatial analysis revealed that high IRs (hotspots) were clustered in the central-northern region of Peninsular Malaysia. In the demographic aspect, knowlesi malaria was more prevalent in male and age between 20 and 39. Conclusions: This study revealed the spatial and temporal patterns of P. knowlesi in Peninsular Malaysia throughout 2011 to 2018 . Knowlesi malaria control strategy should be emphasized in Malaysia malaria eradication program.

\section{Background}

Over the decades, malaria has persisted as one of the most important vector-borne parasitic diseases globally. Its impacts are geographically variable, depending on the intensity of transmission and parasite species involved [1]. According to the World Health Organization report, an estimated 228 million malaria cases were reported in at least 80 countries and territories in 2018 [2]. With the effort of roll back malaria activity, there has been a significant progress in reducing malaria morbidity and mortality through strategies such as comprehensive disease surveillance, distribution of insecticide-treated bed nets and the use of highly effective artemisinin combination medications [2].

In Malaysia, the Malaria Eradication Programme was introduced in 1967, which continued to the $80 \mathrm{~s}$. The programme has resulted in significant reduction of malaria cases by approximately $94.3 \%$ in Peninsular Malaysia [3]. Incidence of human malaria from Plasmodium vivax and Plasmodium falciparum have dropped steadily nationwide. However, the emergence of zoonotic malaria caused by Plasmodium knowlesi has put Malaysia into world attention because the species is the main cause of clinical malaria in the country [1]. This has certainly become a great challenge to Malaysia's efforts to eliminate malaria.

Plasmodium knowlesi is a simian malaria parasite which is prevalent in Southeast Asia and gaining prominence for its increasing human cases [4]. Clinical manifestations typically include fever, chills, headache, malaise, rigors, and anorexia [5]. Infection caused by this parasite species can sometimes be highly life-threatening. It is often misdiagnosed via microscopy as Plasmodium malariae infection due to morphology similarities between the two species at trophozoite, schizont, and gametocyte stages [6, 7]. Plasmodium knowlesi is transmitted to human from non-human primates via bite of forest-dwelling Anopheles mosquitoes from the Leucosphyrus group [8]. Both vectors and hosts of $P$. knowlesi are naturally distributed in Southeast Asia, hence, it is likely that this parasite is geographically confined.

Malaria case detection in Peninsular Malaysia is contributed by three systems, which are active case detection (ACD), mass blood survey (MBS), and passive case detection (PCD). ACD involves screening for febrile individuals at localities experiencing outbreaks or within high-risk groups such as military, indigenous people, rural settlers, and migrant workers. MBS requires at least $80 \%$ of the community who receive insecticide-treated nets (ITNs) and residual spraying to be tested. Also, MBS is applied as a response during outbreaks, when health officers are required to screen every individual within an outbreak locality. PCD consists of malaria cases detection among patients who go to a health post for treatment on their own initiative. Most of the confirmed human and simian malaria cases were detected through PCD approach.

Except for case detection, understanding spatial distributions of $P$. knowlesi infection is also important for resource allocation. Spatial analysis is commonly used for disease hotspot identification and evaluation of patterns of epidemics. Several studies have used spatial-temporal analysis to detect clustering of malaria $[9,10,11]$. A better understanding on spatial variations in knowlesi malaria distribution is useful to improve intervention programme and health resource allocation. Besides, cluster detection can aid in more emphasized epidemiological surveillance of reservoir hosts and research on bionomics of vectors. Recently, research based on spatial-temporal analysis has been conducted extensively to study malaria distribution in Sabah, Malaysian Borneo [12, 13, 14]. However, similar study to investigate transmission patterns in the Peninsular Malaysia is lacking. Therefore, we aimed to use spatial-temporal analysis using district level data to identify P. knowlesi infection hotspots in Peninsular Malaysia between 2011 and 2018. Furthermore, state-wide demographic parameters of knowlesi malaria in Peninsular Malaysia was also investigated to reveal fundamental epidemiological characteristics of the $P$. knowlesi infections.

\section{Methods}

\section{Geography and demography of study areas}

Malaysia is a country in Southeast Asia and it is separated by South China Sea into two regions, Peninsular Malaysia and Malaysian Borneo. The national census in 2010 estimated the total population of Malaysia at 28.3 million [15]. The annual citizen population growth rate was projected at $1.6 \%$ in 2010 . However, the growth rate declined to $1.1 \%$ in 2018 .

Loading [MathJax]/jax/output/CommonHTML/jax.js 
Our study area primarily focused on Peninsular Malaysia which spreads from latitude $1^{\circ} 15^{\prime} 50.0^{\prime \prime} \mathrm{N}$ to $6^{\circ} 43^{\prime} 36^{\prime \prime} \mathrm{N}$ and from longitude $99^{\circ} 35^{\prime} \mathrm{E}$ to $104^{\circ} 36^{\prime}$ E. Peninsular Malaysia covers a land area of 13.21 million hectares (Fig. 1) [16]. Forested areas accounted for approximately 5.76 million hectares which is equivalent to $43.6 \%$ of the land area of Peninsular Malaysia [16]. The climate is categorized as equatorial, typically hot and humid throughout the year. Rainfall pattern in Peninsular Malaysia is mainly influenced by the southwest monsoon season (from May to August) and northeast monsoon season (from November to February) [17]. The annual rainfall ranges from a maximum of 5000 mm and a minimum of $1750 \mathrm{~mm}$. Mean daily temperature ranges from $25^{\circ} \mathrm{C}$ to $28^{\circ} \mathrm{C}$.

Peninsular Malaysia is divided into 11 states (Perlis, Kedah, Pulau Pinang, Perak, Selangor, Negeri Sembilan, Melaka, Johor, Kelantan, Terengganu, and Pahang) and 2 federal territories (Kuala Lumpur and Putrajaya) (Fig. 1). Approximately $24.7 \%$ of the population of Peninsular Malaysia reside in sub-urban and rural areas.

\section{Data Sources}

Laboratory-confirmed knowlesi malaria case data for the period 2011-2018 were provided by the Ministry of Health of Malaysia. This dataset contains information of each confirmed case, including state, district, year, nationality, ethnicity, citizenship, occupation, age, gender, and origin of infection (indigenous and imported cases). An indigenous malaria case is a case contracted locally with no evidence of importation and no direct link to transmission from an imported case whereas imported malaria is a case in which the infection was acquired outside the area in which it is diagnosed [18]. In our study, we considered an imported case as a case which was acquired outside of Malaysia. The population data of Peninsular Malaysia was obtained from the Department of Statistics Malaysia open-source platform [15, 19]. The descriptive epidemiological analysis was conducted at state level to show the demographic characteristics of indigenous and imported $P$. knowlesi infection cases separately. Demographic characteristics of imported cases involved both local and foreign citizens who had international travel history and contracted the disease outside of Malaysia. The case data are available at both state and district levels; however, we aggregated the data by district based on locations where the cases were reported for subsequent analysis.

\section{Spatial analysis of P. knowlesi malaria in Peninsular Malaysia}

Spatial analysis was conducted at district level in Peninsular Malaysia for the period 2011-2018. The annual square root transformed incidence rate (IR) per million people for each district was calculated to deal with the highly skewness of raw incidence rate caused by outliers and deviation from normality of variance. We used the population estimates from the 2010 National Census data [15] and annual state population growth estimation from the Department of Statistics Malaysia [19] to calculate the annual mid-year population for each district from 2011 to 2018 , assuming that the population growth rate of each district was the same as the state's population growth. The calculated annual mid-year population was used to estimate annual incidence rates accurately.

Both global and local Moran's / statistics were performed to identify the spatial autocorrelation and disease hotspots in the study area. First order queen contiguity spatial weight matrix was generated to define districts with shared borders and vertices as neighbours for subsequent analysis.

Global Moran's / test can be used to detect spatial autocorrelation of $P$. knowlesi infection. Global Moran's / provides continuous index value which can be an indication of random distribution (value of zero or close to zero), clustered distribution (value close to +1.0 ), or dispersed distribution (value close to -1.0) [20]. The equation for Global Moran's /is:

$$
I=\frac{n \sum_{i=1}^{n} \sum_{j=1}^{n} w_{i j}\left(x_{i}-\bar{x}\right)\left(x_{j}-\bar{x}\right)}{\left(\sum_{i=1}^{n} \sum_{j=1}^{n} w_{i j}\right) \sum_{i=1}^{n}\left(x_{i}-\bar{x}\right)^{2}}
$$

where $n$ is the number of observations, $\boldsymbol{x}$ is the mean of the variable, $x_{i}$ is the variable value at a particular location, $x_{j}$ is the variable value at another location, $w_{i j}$ is a weight indexing location of $i$ relative to $j$.

Local Moran's I analysis involves formation of Local Indicators of Spatial Association (LISA) statistic to detect the statistically significant spatial cluster of disease (hotspots and cold spots) as well as to identify outliers. A local Moran statistic for an observation $i$ can be set out as below:

$$
I_{i}=z_{i} \sum_{j} w_{i j} Z_{j}
$$

LISA values present four types of cluster: high-high, low-low, high-low, and low-high [21]. High-high clusters are associated with high IR areas (hotspots) whereas low-low clusters are associated with low IR areas (cold spots). High-low and low-high categories represent outliers. The statistic infarannac af hath tacte wara norfarmad hiv Monte Carlo simulation with significant level of $p$-value at 0.05 . Global and Local Moran's / tests were Loading [MathJax]/jax/output/CommonHTML/jax.js

Page $3 / 18$ 
performed using GeoDa 1.14 (University of Chicago, Illinois, USA). Data visualization were carried out by QGIS 3.6.3 (Open Source Geospatial Foundation, Oregon, USA) to demonstrate the spatial and temporal patterns of knowlesi malaria in Peninsular Malaysia from 2011 to 2018.

\section{Results}

\section{Demographic characteristics of knowlesi malaria from 2011 to 2018}

The demographic characteristics of indigenous knowlesi malaria cases in Peninsular Malaysia are shown in Table 1. From 2011 to $2018,2,587$ indigenous knowlesi malaria cases were reported in Peninsular Malaysia. Indigenous cases were more prevalent among the Malays (58.7\%) as compared to other ethnics. Foreigners made up $16.4 \%$ of the indigenous cases. Forest related occupations contributed $53.96 \%$ of the total indigenous cases. One-third of the total indigenous cases were reported among estate, farm, and plantation workers (Table 1, Additional file 1: Figure S1) 
Table 1

Demographic characteristics of indigenous knowlesi malaria cases in Peninsular Malaysia from 2011 to 2018.

\begin{tabular}{|c|c|}
\hline Variable & $\mathrm{N}(\%)$ \\
\hline \multicolumn{2}{|l|}{ Age group } \\
\hline 0 to 9 & $53(2.0)$ \\
\hline 10 to 19 & $249(9.6)$ \\
\hline 20 to 29 & $624(24.1)$ \\
\hline 30 to 39 & 707 (27.3) \\
\hline 40 to 49 & $437(16.9)$ \\
\hline 50 to 59 & $314(12.1)$ \\
\hline 60 and above & $203(7.8)$ \\
\hline \multicolumn{2}{|l|}{ Gender } \\
\hline Male & $2167(83.8)$ \\
\hline Female & $420(16.2)$ \\
\hline \multicolumn{2}{|l|}{ Ethnicity } \\
\hline Chinese & $145(5.6)$ \\
\hline Indian & $44(1.7)$ \\
\hline Malay & $1518(58.7)$ \\
\hline Orang Asli (aborigine community) & $372(14.4)$ \\
\hline Sabahan & $27(1.0)$ \\
\hline Sarawakian & $34(1.3)$ \\
\hline Others & $429(16.6)$ \\
\hline No data & $18(0.7)$ \\
\hline \multicolumn{2}{|l|}{ Occupation class } \\
\hline Agroculture \& fishery & $20(0.8)$ \\
\hline Army \& police* & $138(5.3)$ \\
\hline Children \& students & $224(8.7)$ \\
\hline Construction & $98(3.8)$ \\
\hline Ecotourism, forest, \& wildlife management* & $39(1.5)$ \\
\hline Estate, farm, \& plantation workers* & $897(34.7)$ \\
\hline Factory workers & $55(2.1)$ \\
\hline Forest resource gatherers* & $82(3.2)$ \\
\hline Logging* & $121(4.7)$ \\
\hline Logistics \& transportation & $43(1.7)$ \\
\hline Mining* & $51(2.0)$ \\
\hline Other manual workers \& skilled labours & $134(5.2)$ \\
\hline Village labours* & $68(2.6)$ \\
\hline Others & $365(14.1)$ \\
\hline Unemployed & $241(9.3)$ \\
\hline No data & $11(0.4)$ \\
\hline
\end{tabular}




\begin{tabular}{|ll|}
\hline Variable & N (\%) \\
\hline Citizenship & \\
\hline Locals & $2161(83.5)$ \\
\hline Foreigners & $423(16.4)$ \\
\hline No data & $3(0.1)$ \\
\hline * Occupations with exposure to forest & \\
\hline
\end{tabular}

The age and gender distribution of indigenous knowlesi malaria cases according to state were characterized (Table 2, Table 3). Knowlesi malaria was significantly more prevalent in population aged between 20-29 years for Kelantan, Negeri Sembilan, and Pahang, and aged 30-39 years for Johor, Kedah, Perak, Selangor, and Terengganu (Table 2). The proportion of knowlesi malaria among males was generally higher than females in most states (Table 3).

Table 2

Age-based distribution of indigenous knowlesi malaria according to states from 2011 to 2018.

\begin{tabular}{|c|c|c|c|c|c|c|c|c|c|c|c|c|}
\hline \multirow{2}{*}{$\begin{array}{l}\text { Age } \\
\text { group }\end{array}$} & \multicolumn{12}{|c|}{ Number of indigenous knowlesi malaria monoinfection cases according to states (\%) } \\
\hline & Johor & Kedah & Kelantan & Melaka & $\begin{array}{l}\text { Negeri } \\
\text { Sembilan }\end{array}$ & Pahang & Perak & Perlis & $\begin{array}{l}\text { Pulau } \\
\text { Pinang }\end{array}$ & Selangor & Terengganu & $\begin{array}{l}\text { Kuala } \\
\text { Lumpur }\end{array}$ \\
\hline \multirow[t]{2}{*}{0 to 9} & 0 & 1 & 18 & 0 & 3 & 16 & 14 & 0 & 0 & 1 & 0 & 0 \\
\hline & $(0.0)$ & (1.7) & $(2.7)$ & $(0.0)$ & $(2.5)$ & $(2.4)$ & (2.7) & $(0.0)$ & $(0.0)$ & $(0.5)$ & $(0.0)$ & $(0.0)$ \\
\hline \multirow{2}{*}{$\begin{array}{l}10 \text { to } \\
19\end{array}$} & 4 & 0 & 83 & 1 & 6 & 59 & 60 & 0 & 1 & 24 & 11 & 0 \\
\hline & $(2.4)$ & $(0.0)$ & (12.2) & (14.3) & (5.1) & (8.9) & (11.6) & $(0.0)$ & (16.7) & (11.4) & $(6.9)$ & $(0.0)$ \\
\hline \multirow{2}{*}{$\begin{array}{l}20 \text { to } \\
29\end{array}$} & 47 & 8 & 165 & 2 & 39 & 167 & 107 & 0 & 0 & 55 & 34 & 0 \\
\hline & $(28.5)$ & (13.3) & & $(28.6)$ & (33.1) & & (20.7) & $(0.0)$ & $(0.0)$ & $(26.2)$ & (21.3) & $(0.0)$ \\
\hline \multirow{2}{*}{$\begin{array}{l}30 \text { to } \\
39\end{array}$} & 58 & 24 & 176 & 1 & 24 & 163 & 137 & 1 & 2 & 66 & 55 & 0 \\
\hline & (35.2) & $(40.0)$ & $(26.0)$ & (14.3) & (20.3) & & (26.4) & $(100.0)$ & (33.3) & (31.4) & (34.4) & $(0.0)$ \\
\hline \multirow{2}{*}{$\begin{array}{l}40 \text { to } \\
49\end{array}$} & 33 & 12 & 114 & 1 & 19 & 108 & 93 & 0 & 0 & 29 & 27 & 1 \\
\hline & & $(20.0)$ & & (14.3) & (16.1) & & (18.0) & $(0.0)$ & $(0.0)$ & (13.8) & (16.9) & $(100.0)$ \\
\hline \multirow{2}{*}{$\begin{array}{l}50 \text { to } \\
59\end{array}$} & 17 & 12 & 75 & 1 & 17 & 86 & 66 & 0 & 1 & 20 & 19 & 0 \\
\hline & (10.3) & $(20.0)$ & (11.1) & (14.3) & (14.4) & (13.0) & (12.7) & $(0.0)$ & (16.7) & (9.5) & (11.9) & $(0.0)$ \\
\hline \multirow{2}{*}{$\begin{array}{l}60 \& \\
\text { above }\end{array}$} & 6 & 3 & 47 & 1 & 10 & 64 & 41 & 0 & 2 & 15 & 14 & 0 \\
\hline & (3.6) & $(5.0)$ & $(6.9)$ & (14.3) & (8.5) & (9.7) & $(7.9)$ & $(0.0)$ & (33.3) & $(7.1)$ & (8.8) & $(0.0)$ \\
\hline \multirow[t]{2}{*}{ Total } & $\begin{array}{l}165 \\
(100.0)\end{array}$ & $\begin{array}{l}60 \\
(100.0)\end{array}$ & $\begin{array}{l}678 \\
(100.0)\end{array}$ & $\begin{array}{l}7 \\
(100.0)\end{array}$ & $\begin{array}{l}118 \\
(100.0)\end{array}$ & $\begin{array}{l}663 \\
(100.0)\end{array}$ & $\begin{array}{l}518 \\
(100.0)\end{array}$ & 1 & $\begin{array}{l}6 \\
(100.0)\end{array}$ & $\begin{array}{l}210 \\
(100.0)\end{array}$ & 160 & 1 \\
\hline & & & & & & & & $(100.0)$ & & & $(100.0)$ & $(100.0)$ \\
\hline
\end{tabular}


Table 3

Gender-based distribution of indigenous knowlesi malaria cases according to states from 2011 to 2018.

\begin{tabular}{|llll|}
\hline State & \multicolumn{2}{l}{ Number of indigenous knowlesi malaria monoinfection cases according to gender (\%) } & \multicolumn{1}{l}{ Total (\%) } \\
\cline { 2 - 3 } & Male & Female & $165(100.00)$ \\
\hline Johor & $157(93.15)$ & $8(4.85)$ & $60(100.00)$ \\
\hline Kedah & $56(93.33)$ & $4(6.67)$ & $678(100.00)$ \\
\hline Kelantan & $576(84.96)$ & $102(15.04)$ & $7(100.00)$ \\
\hline Melaka & $6(85.71)$ & $1(14.29)$ & $118(100.00)$ \\
\hline Pahang & $546(82.35)$ & $20(16.95)$ & $663(100.00)$ \\
\hline Perak & $414(79.92)$ & $117(17.65)$ & $518(100.00)$ \\
\hline Perlis & $1(100.00)$ & $104(20.08)$ & $1(100.00)$ \\
\hline Pulau Pinang & $4(66.66)$ & $0(0.00)$ & $6(100.00)$ \\
\hline Selangor & $181(86.19)$ & $2(33.33)$ & $210(100.00)$ \\
\hline Terengganu & $128(80.00)$ & $29(13.81)$ & $160(100.00)$ \\
\hline Kuala Lumpur & $0(0.00)$ & $32(20.00)$ & $1(100.00)$ \\
\hline
\end{tabular}

Table 4 and Table 5 show the distribution of imported knowlesi malaria cases by state and nationality of the patients. Kelantan recorded the highest cumulative number of imported knowlesi malaria cases (129 cases), followed by Johor (12 cases), and Selangor (8 cases) (Table 4, Fig. 2 ). Of these imported cases in Kelantan, 121 cases (93.8\%) were reported in Gua Musang district. The most common nationality of the imported knowlesi malaria patients were Indonesian (27.21\%), local Malaysian (7.47\%) and Thai (8.88\%).

Table 4

Imported knowlesi malaria cases according to states from 2011 to 2018.

\begin{tabular}{|lllllllllll|}
\hline \multirow{2}{*}{ State } & \multicolumn{9}{l}{ Annual number of imported knowlesi malaria cases } & \multicolumn{2}{c}{ Total } \\
\cline { 2 - 5 } & 2011 & 2012 & 2013 & 2014 & 2015 & 2016 & 2017 & 2018 & \\
\hline Kelantan & 36 & 31 & 37 & 21 & 0 & 1 & 2 & 1 & 129 \\
\hline Kedah & 0 & 0 & 0 & 1 & 0 & 0 & 0 & 0 & 1 \\
\hline Pahang & 0 & 1 & 2 & 0 & 0 & 0 & 0 & 0 & 3 \\
\hline Perak & 2 & 0 & 2 & 0 & 0 & 0 & 0 & 2 & 6 \\
\hline Negeri Sembilan & 1 & 0 & 1 & 1 & 0 & 0 & 0 & 0 & 3 \\
\hline Johor & 0 & 2 & 1 & 5 & 3 & 1 & 0 & 0 & 12 \\
\hline Selangor & 1 & 2 & 1 & 2 & 1 & 0 & 0 & 1 & 8 \\
\hline Pulau Pinang & 1 & 0 & 1 & 0 & 0 & 0 & 1 & 0 & 3 \\
\hline Melaka & 0 & 0 & 0 & 0 & 0 & 0 & 1 & 0 & 1 \\
\hline Kuala Lumpur & 1 & 0 & 0 & 0 & 0 & 1 & 0 & 0 & 2 \\
\hline Terengganu & 0 & 0 & 1 & 0 & 0 & 0 & 0 & 0 & 1 \\
\hline Perlis & 0 & 0 & 0 & 0 & 0 & 0 & 0 & 0 & 0 \\
\hline Total & 42 & 36 & 46 & 30 & 4 & 3 & 4 & 4 & \\
\hline
\end{tabular}


Table 5

Imported knowlesi malaria cases according to nationality from 2011 to

\begin{tabular}{|ll|}
\hline Nationality & Frequency (\%) \\
\hline Bangladesh & $4(2.37)$ \\
\hline Cambodia & $2(1.18)$ \\
\hline India & $4(2.37)$ \\
\hline Indonesia & $46(27.21)$ \\
\hline Ireland & $1(0.59)$ \\
\hline Myanmar & $11(6.51)$ \\
\hline Pakistan & $6(3.55)$ \\
\hline Philippines & $1(0.59)$ \\
\hline Sudan & $1(0.59)$ \\
\hline Thailand & $15(8.88)$ \\
\hline Vietnam & $1(0.59)$ \\
\hline Local & $16(7.47)$ \\
\hline Unknown nationality & $61(36.09)$ \\
\hline Total & $169(100.00)$ \\
\hline
\end{tabular}

\section{Knowlesi malaria trends in Peninsular Malaysia from 2011 to 2018}

Between 2011 and 2018, a total of 2,767 P. knowlesi monoinfection cases were reported in Peninsular Malaysia. Of these cases, 812 (29.35\%) were from Kelantan state, while 666 (24.07\%) and 524 (18.94\%) were from Pahang and Perak respectively (Table 6). The reported case increased from 2011 to 2014, followed by a transient drop in 2015 and 2016 prior to gradual increase (Fig. 3). In 2011, 277 cases were reported, and the number of cases recorded in 2018 was 598. Similar trend could be observed in the IR of five states: Kelantan, Pahang, Perak, Terengganu, and Negeri Sembilan. However, the IR in Kelantan and Negeri Sembilan dropped in 2018 as compared to 2017 (Fig. 4). Federal Territory of Kuala Lumpur, Pulau Pinang, Melaka, and Perlis had IR lower than 1.5 annually. No knowlesi malaria case was reported in the Federal Territory of Putrajaya throughout the study duration. 
Table 6

Number of cases of knowlesi malaria in Peninsular Malaysia and by states from 2011 to 2018.

\begin{tabular}{|c|c|c|c|c|c|c|c|c|c|c|}
\hline & \multicolumn{8}{|c|}{ Annual number of knowlesi malaria cases } & \multirow[t]{2}{*}{ Total } & \multirow[t]{2}{*}{$\%$} \\
\hline & 2011 & 2012 & 2013 & 2014 & 2015 & 2016 & 2017 & 2018 & & \\
\hline Peninsular Malaysia & 277 & 414 & 474 & 332 & 113 & 136 & 423 & 598 & 2767 & 100 \\
\hline \multicolumn{11}{|l|}{ States } \\
\hline Johor & 7 & 14 & 22 & 15 & 18 & 12 & 47 & 42 & 177 & 6.40 \\
\hline Kedah & 1 & 5 & 4 & 9 & 1 & 4 & 10 & 29 & 63 & 2.28 \\
\hline Kelantan & 111 & 148 & 152 & 99 & 20 & 34 & 135 & 113 & 812 & 29.35 \\
\hline Melaka & 0 & 1 & 1 & 0 & 0 & 0 & 2 & 4 & 8 & 0.29 \\
\hline Negeri Sembilan & 3 & 18 & 25 & 12 & 2 & 3 & 30 & 30 & 123 & 4.45 \\
\hline Pahang & 52 & 104 & 136 & 106 & 39 & 33 & 77 & 119 & 666 & 24.07 \\
\hline Perak & 49 & 55 & 64 & 59 & 19 & 27 & 76 & 175 & 524 & 18.94 \\
\hline Perlis & 0 & 0 & 0 & 0 & 0 & 0 & 0 & 1 & 1 & 0.04 \\
\hline Pulau Pinang & 3 & 4 & 2 & 0 & 0 & 0 & 1 & 1 & 11 & 0.40 \\
\hline Selangor & 30 & 38 & 40 & 19 & 8 & 14 & 24 & 45 & 218 & 7.88 \\
\hline Terengganu & 20 & 27 & 28 & 13 & 6 & 8 & 21 & 38 & 161 & 5.82 \\
\hline $\begin{array}{l}\text { Federal Territory of } \\
\text { Kuala Lumpur }\end{array}$ & 1 & 0 & 0 & 0 & 0 & 1 & 0 & 1 & 3 & 0.11 \\
\hline $\begin{array}{l}\text { Federal Territory of } \\
\text { Putrajaya }\end{array}$ & 0 & 0 & 0 & 0 & 0 & 0 & 0 & 0 & 0 & 0.00 \\
\hline
\end{tabular}

\section{District Level Spatial-temporal Distribution Of Knowlesi Malaria Incidence}

The district-level knowlesi malaria IR from 2011 to 2018 is illustrated in Fig. 5. Overall, the spatial patterns of knowlesi malaria incidences were relatively consistent and higher transmissions were observed in the central-northern region of Peninsular Malaysia. Gua Musang and Lipis districts were found to consistently record IR > 10 annually throughout the study period. In 2015, there was a transient drop in incidence of knowlesi malaria in almost all districts comparing to previous years. Only two districts were reported to have IR > 10 in the same year. Knowlesi malaria incidence peaked in 2018 with 17 districts reporting $I R>10$.

The spatial autocorrelation of knowlesi malaria was evaluated using 2011-2018 summarized cases. Global Moran's / test revealed a statistically significant and positive spatial autocorrelation in the study area (Global Moran's $I=0.489, P<0.001, z=7.14$ ). This indicated that there was a spatial dependence and clustering of knowlesi malaria incidence in Peninsular Malaysia. Local Moran's /test identified major hotspots (high-high spatial clusters) involving 10 districts (Table 7, Fig. 6). Three cold spots (low-low spatial clusters) comprising seven districts were identified near major cities. All hotspots were located in regions with low population density (averagely 34 people per square km) whereas cold spots comprised locations with high population density (averagely 1305 people per square km). Low-high spatial cluster were identified in two districts. These two districts (Kinta and Cameron Highlands) have low incidence of knowlesi malaria but surrounded by districts with high incidence of disease. Kinta and Cameron Highlands had population density of 617 people per square $\mathrm{km}$ and 58 people per square km respectively 
Table 7

Statiscally significant district-level spatial clusters of knowlesi malaria based on IR, 20112018.

\begin{tabular}{|c|c|c|c|c|c|}
\hline Cluster type & District & Number of cases & IR & LISA Index & $P$-value \\
\hline \multirow[t]{10}{*}{ High-high } & Jeli & 95 & 46.24 & 5.88 & 0.001 \\
\hline & Kuala Krai & 167 & 37.35 & 2.92 & 0.002 \\
\hline & Jerantut & 101 & 32.28 & 2.16 & 0.001 \\
\hline & Lipis & 329 & 58.70 & 5.97 & 0.003 \\
\hline & Raub & 66 & 25.49 & 1.51 & 0.001 \\
\hline & Batang Padang & 122 & 25.64 & 0.66 & 0.048 \\
\hline & Hulu Perak & 98 & 32.23 & 2.14 & 0.001 \\
\hline & Kuala Kangsar & 84 & 22.57 & 0.74 & 0.039 \\
\hline & Hulu Terengganu & 68 & 29.42 & 1.36 & 0.006 \\
\hline & Gua Musang & 506 & 71.68 & 6.88 & 0.001 \\
\hline \multirow[t]{7}{*}{ Low-low } & Kota Bharu & 1 & 1.36 & 0.48 & 0.007 \\
\hline & Kota Setar & 1 & 1.60 & 0.48 & 0.011 \\
\hline & Yan & 0 & 0.00 & 0.57 & 0.034 \\
\hline & Klang & 1 & 1.03 & 0.54 & 0.009 \\
\hline & Kuala Langat & 0 & 0.00 & 0.54 & 0.039 \\
\hline & Petaling & 3 & 1.22 & 0.44 & 0.009 \\
\hline & Sepang & 1 & 2.07 & 0.36 & 0.028 \\
\hline \multirow[t]{2}{*}{ Low-high } & Cameron Highlands & 2 & 6.99 & -0.58 & 0.001 \\
\hline & Kinta & 48 & 7.78 & -0.25 & 0.004 \\
\hline
\end{tabular}

\section{Discussion}

This study reveals that $P$. knowlesi infections were distributed across all age groups with higher prevalence among adults of the age group of $20-39$ years, notably males, who likely are more active outdoors and have greater forest exposure to infection due to job opportunities [22]. A small segment of knowlesi malaria cases was observed among children and the elderly which could be associated with limited outdoor activities and lower risk of biting by infected Anopheles mosquito.

Individuals infected with knowlesi malaria were involved in various types of occupation. However, more than half (53.96\%) of them had occupations related to agriculture and forest. Nonetheless, types of occupation alone may not give a true reflection of risk of knowlesi malaria infection.

Recreational activities related to forest such as bird watching, hiking, and camping may also expose an individual to infective mosquito bite. Rural and sub-urban settlements located close to forest-edge and forested areas, are mostly resided by Malay community, which suggests greater burden of $P$. knowlesi infection among Malays compared with other ethnic groups. Although $16.4 \%$ of the total indigenous cases were foreign citizens, the distribution of cases by nationality may not be an important factor. The most important risk factors probably are activities that expose them to bites of infective mosquitoes.

Besides, demography analysis of imported cases revealed that one-fourth of the imported cases were of Indonesian nationality. Imported cases involving Malaysians were most potentially due to international travel to knowlesi malaria endemic countries. Besides Malaysia, $P$. knowlesi infections have been reported throughout Southeast Asia including Indonesia [23], Vietnam [24], Thailand [25], and Cambodia [26].

In this study, Kelantan, Pahang, and Perak had consistently recorded high burden of knowlesi malaria. These states have the largest settlement of aborigine communities [27]. Aborigine individuals made up one-tenth of the total indigenous knowlesi malaria cases. Prior to our study, human malaria parasites had been frequently reported among aborigine population in Peninsular Malaysia [28, 29, 30]. Moreover, researchers detected presence of submicroscopic $P$. knowlesi infections among asymptomatic individuals within these communities [31]. Aborigine communities are considered high-risk of exposure to malaria. This is due to their settlements being located in the forest fringes and many are still dependent on forest resources for subsistence [32,33]. 
Spatial analysis indicated high incidence rate of knowlesi malaria concentrated in the central-northern region of Peninsular Malaysia. Of these regions, Gua Musang and Lipis districts reported the highest incidence rate compared to other districts. Gua Musang and Lipis are neighbouring districts and most of the infected patients worked in agricultural sector, implying frequent exposure to forest, forestedge, plantation setting, with increased probability of contact with Anopheles mosquitoes as well as macaque populations. Prior to 2015, many agriculture, logging, and quarrying activities occurred in the Gua Musang district [34]. These activities were involved with exploitation of secondary forests and permanent forest reserves, which potentially lead to spill over of macaque population to human settlements. Natural infection of simian malaria in human tends to occur when human encroached into normal mosquito-monkey circulations in the forested area [35].

A decline in knowlesi malaria incidence was observed in 2015 and 2016, whereby the number of knowlesi malaria reported in Peninsular Malaysia dropped below 150 cases annually. This trend might be a transient phenomenon and might not possibly due to systematic or sustained factors. Possible explanations to this change include transient reduction in case detection activities, reduction in vector density, reduction in macaque population, or reduction in human-mosquito contacts. Malaria elimination efforts were intensified to reduce population of vectors responsible for human malaria such as $P$. malariae, $P$. vivax, and $P$. falciparum which these could have temporarily reduced $P$. knowlesi vector population as well. These measures include distribution of ITNs, larvaciding, residual spraying, and repellents to the high-risk groups in order to reduce malaria vector population and human-mosquito contacts. Otherwise, the El Nino phenomenon which led to anomalous rainfall pattern and strong drought in Southeast Asia in 2015 , accompanied with severe haze episodes could have contributed to changes in vector density and reduced malaria transmission [12,36, 37].

A significant rebound of knowlesi malaria transmission was observed after 2016 . This may be due to drastic changes in the transmission dynamics of the parasite between human, macaques and vectors caused by agricultural expansion and forest exploration. According to the Forestry Department of Peninsular Malaysia statistical report, approximately one million hectares of total forested areas have been loss from 2016 to 2018 and permanent reserved forest area recorded decrease from 4.92 million hectares (in 2016) to 4.80 million hectares (in 2018) [16]. Peninsular Malaysia has experienced large-scale deforestation due to intensified agricultural activities such oil palm and rubber, timber production and rapid urban expansion since 1970s [38]. Establishment of crop plantation increases the vectors' natural breeding site and increases human exposure to vectors' breeding sites [39]. Unlike in human malaria transmission, susceptible knowlesi malaria individuals are usually exposed to agricultural settings or forests instead of at home or its surrounding areas due to the exophagic nature of the vectors [40]. In Sabah, higher $P$. knowlesi transmission was observed in large intact forest patches within five km of households, pulpwood plantations within three km of households, and oil palm plantations with fragmented landscapes [13]. Malaria elimination strategies such as ITN and residual spraying applied within the vicinity of houses have proven to be effective in interrupting human malaria transmission but less protective against simian malaria vectors which feed predominantly in the forest. However, personal insecticide usage has proven to reduce risk of exposure to $P$. knowlesi [13]. Although there are efforts of distributing repellents for agricultural workers, it is very dependent on the individuals' active participation in using these repellents routinely at work.

As both Peninsular Malaysia and Malaysian Borneo share similar geographical and cultural characteristics to a certain extent, there are other comparative points from previous studies which can reflect on the transmission of $P$. knowlesi infections in Peninsular Malaysia. It is noted that both Peninsular Malaysia and Malaysian Borneo experienced an increase in $P$. knowlesi despite a dramatic decline in other human malaria parasite infections [14]. In Sabah, higher rainfall was associated with increase in knowlesi malaria cases after three months [12, 41]. Increase in rainfall causes formation of water pockets which are ideal for mosquito breeding. Nevertheless, a combination of environmental factors including temperature, rainfall, humidity, and land use could serve as predictors for disease transmission. In addition, community-level surveillance using serological markers demonstrated that $P$. knowlesi exposure was positively associated with age, male sex, forest activity, and contact with macaques but negatively associated with personal insecticide practice and higher altitude [13,42]. Further studies should be conducted to understand the environmental and exposure risks based on these factors particularly in Peninsular Malaysia.

In this study, some districts in Perak, Kelantan, Pahang, and Terengganu states were found to demonstrate knowlesi malaria spatial clustering as hotspots. These findings can guide malaria control programme in strategizing effective malaria intervention which put more focus on these districts. Moreover, the monitoring of districts clustered as hotspots is crucial because disease transmission may spill over to their neighbours due to crossdistrict migration of macaque populations with potential carriage of malaria parasites or long-distance spread of infective vectors. Studies in Africa suggested that some species of malaria vectors are capable of flying over hundreds of kilometers [43, 44]. Thus far, the migratory behaviours of malaria vector species in Malaysia are not fully understood and this has certainly opened a knowledge gap for further studies to determine connectivity between bionomics of vectors and malaria incidence.

This is the first study which utilized spatial data analysis to generate spatial-temporal distribution of knowlesi malaria at district scale covering the entire Peninsular Malaysia. Nonetheless, there were several limitations to this study. Firstly, the study was descriptive in nature, with no control group for comparison purposes. Therefore, we were not able to establish risk factors such as sociodemographic factors Secondly, we did not include environmental parameters in the analysis which are important to better describe the transmission dynamics of $P$. knowlesi in the study area. Further study could be conducted by taking into consideration how environmental variations could impact the transmission of knowlesi malaria. Climatic factors such as rainfall, relative humidity, temperature, water bodies and normalized difference vegetation index can be used to spatially assess malaria risk factors. While Malaysia is moving forward to end transmission of human malaria, the emergence of $P$. knowlesi could became the next

Loading [MathJax]/jax/output/CommonHTML/jax.js 
challenge to the malaria programme. Advancement in our knowledge about the ecology of $P$. knowlesi could help policy maker to develop control strategies which are effectively in Peninsular Malaysia.

\section{Conclusions}

This study highlighted the spatial and temporal patterns of $P$. knowlesi at district spatial scale level from 2011 to 2018 in Peninsular Malaysia. The findings from this study could assist malaria programme in targeting knowlesi malaria high burden zones in Peninsular Malaysia for programmatic intervention.

\section{Abbreviations}

IR

square root transformed incidence rate (per million people)

I

Moran's index

ITN

Insecticide-treated nets

ACD

Active case detection

MBS

Mass blood survey

PCD

Passive case detection

$P$

p-value

Z

z-score

\section{Declarations}

Acknowledgements

The authors thank Ministry of Health Malaysia for providing data in supporting this study.

Authors contributions'

WKP, TWC, YLL, and MYF conceptualized and designed the study. MHAH, JJ, and RNM involved in the data collection and provided the dataset for analysis. WKP and TWC conducted the data analysis. WKP wrote the manuscript. All authors reviewed, revised, and approved the final manuscript.

\section{Funding}

This study was supported by the Ministry of Education Malaysia (grant number LR002A-2018) and the Ministry of Science and Technology, Taiwan (MOST108-2638-H-002-002-MY2).

Availability of data and materials

The dataset of this article is available upon reasonable request.

Ethics approval and consent to participate

This study was registered with the National Medical Research Register (NMRR-16-2109-32928) and an ethical approval was obtained from the Malaysian Research Ethical Committee (MREC) [reference no. KKM/NIHSEC/ P16-1782 (11)]. No participant's consent was taken because this study involved only secondary data of all diagnosed and reported knowlesi malaria cases.

Consent for publication

Not applicable

Competing interests

The authors declare that they have no competing interests. 
Authors details

${ }^{1}$ Department of Parasitology, Faculty of Medicine, University of Malaya, Kuala Lumpur, Malaysia

2 Disease Control Division, Ministry of Health Malaysia, Putrajaya, Malaysia

${ }^{3}$ Department of Molecular Parasitology and Tropical Diseases, School of Medicine, College of Medicine, Taipei Medical University, Taipei, Taiwan

\section{References}

1. White NJ, Pukrittayakamee S, Hien TT, Faiz MA, Mokuolu OA, Dondorp AM. Malaria Lancet. 2014;383:723-35.

2. World Health Organization. World malaria report 2019. Geneva: World Health Organization; 2019.

3. Lim ES. Current status of malaria in Malaysia. Southeast Asian J Trop Med Public Health. 1992;23:43-9.

4. White NJ. Plasmodium knowlesi. the fifth human malaria parasite. Clin Infect Dis. 2008;46:172-3.

5. Daneshvar C, Davis TM, Cox-Singh J, Rafa'ee MZ, Zakaria SK, Divis PC, et al. Clinical and laboratory features of human Plasmodium knowlesi infection. Clin Infect Dis. 2009;49:852-60.

6. Cox-Singh J, Davis TM, Lee KS, Shamsul SS, Matusop A, Ratnam S, et al. Plasmodium knowlesi malaria in humans is widely distributed and potentially life threatening. Clin Infect Dis. 2008;46:165-71.

7. Singh B, Kim Sung L, Matusop A, Radhakrishnan A, Shamsul SS, Cox-Singh J, et al. A large focus of naturally acquired Plasmodium knowlesi infections in human beings. Lancet. 2004;363:1017-24.

8. Vythilingam I, Lim YA, Venugopalan B, Ngui R, Leong CS, Wong ML, et al. Plasmodium knowlesi malaria an emerging public health problem in Hulu Selangor, Selangor, Malaysia (2009-2013): epidemiologic and entomologic analysis. Parasit Vectors. $2014 ; 7: 436$.

9. Dhimal M, O'Hara RB, Karki R, Thakur GD, Kuch U, Ahrens B. Spatio-temporal distribution of malaria and its association with climatic factors and vector-control interventions in two high-risk districts of Nepal. Malar J. 2014;13:457.

10. Hundessa SH, Williams G, Li S, Guo J, Chen L, Zhang W, et al. Spatial and space-time distribution of Plasmodium vivax and Plasmodium falciparum malaria in China, 2005-2014. Malar J. 2016;15:595.

11. Mercado CEG, Lawpoolsri S, Sudathip P, Kaewkungwal J, Khamsiriwatchara A, Pan-Ngum W, et al. Spatiotemporal epidemiology, environmental correlates, and demography of malaria in Tak Province, Thailand (2012-2015). Malar J. 2019;18:240.

12. Cooper DJ, Rajahram GS, William T, Jelip J, Mohammad R, Benedict J, et al. Plasmodium knowlesi malaria in Sabah, Malaysia, 2015-2017: ongoing increase in incidence despite near-elimination of the human-only Plasmodium species. Clin Infect Dis. 2020;70:361-7.

13. Fornace KM, Brock PM, Abidin TR, Grignard L, Herman LS, Chua TH, et al. Environmental risk factors and exposure to the zoonotic malaria parasite Plasmodium knowlesi across northern Sabah, Malaysia: a population-based cross-sectional survey. Lancet Planet Health. 2019;3:e179e86.

14. William T, Rahman HA, Jelip J, Ibrahim MY, Menon J, Grigg MJ, et al. Increasing incidence of Plasmodium knowlesi malaria following control of $P$. falciparum and $P$. vivax malaria in Sabah, Malaysia. PLoS Negl Trop Dis. 2013;7:e2026.

15. Department of Statistics Malaysia. Population distribution and basic demographic characteristics 2010. Putrajaya: Department of Statistics Malaysia; 2011.

16. Forestry Department Peninsular Malaysia. Forestry statistics. https://53-46/2016-06-07-03-12-29 (2019). Accessed 21 Dec 2019.

17. Suhaila J, Deni SM, Zin WW, Jemain AAJSM. Trends in peninsular Malaysia rainfall data during the southwest monsoon and northeast monsoon seasons: 1975-2004. Sains Malays. 2010;39:533-42.

18. World Health Organization. WHO malaria terminology. Geneva: World Health Organization; 2019.

19. Malaysia Department of Statistics. Malaysia @ a glance. https://T1AzKORLcEtiZz09 (2019). Accessed 30 Oct 2019.

20. Moran PAP. The interpretation of statistical maps. J R Stat Soc B. 1948;10:243-51.

21. Anselin L. Local indicators of spatial association - LISA. Geogr Anal. 1995;27:93-115.

22. Grigg MJ, Cox J, William T, Jelip J, Fornace KM, Brock PM, et al. Individual-level factors associated with the risk of acquiring human Plasmodium knowlesi malaria in Malaysia: a case-control study. Lancet Planet Health. 2017;1:e97-104.

23. Herdiana H, Irnawati I, Coutrier FN, Munthe A, Mardiati M, Yuniarti T, et al. Two clusters of Plasmodium knowlesi cases in a malaria elimination area, Sabang Municipality, Aceh, Indonesia. Malar J. 2018;17:186.

24. Erhart A, Thang ND, Hung NQ, Toi le V, Hung le X, Tuy TQ, et al. Forest malaria in Vietnam: a challenge for control. Am J Trop Med Hyg. 2004;70:110-8.

25. Jongwutiwes S, Buppan P, Kosuvin R, Seethamchai S, Pattanawong U, Sirichaisinthop J, et al. Plasmodium knowlesi malaria in humans and macaques, Thailand. Emerg Infect Dis. 2011;17:1799-806.

26. Imwong M, Madmanee W, Suwannasin K, Kunasol C, Peto TJ, Tripura R, et al. Asymptomatic natural human infections with the simian malaria Loading [MathJax]/jax/output/CommonHTML/jax.js Plasmodium knowlesi. J Infect Dis. 2019;219:695-702.

Page 13/18 
27. Masron T, Masami F, Ismail N. Orang Asli in Peninsular Malaysia: population, spatial distribution and socio-economic condition. J Ritsumeikan Soc Sci Hum. 2013;6:75-115.

28. Norhayati M, Rohani AK, Hayati MI, Halimah AS, Sharom MY, Abidin AH, et al. Clinical features of malaria in Orang Asli population in Pos Piah, Malaysia. Med J Malaysia. 2001;56:271-4.

29. Liew JWK, Mahpot RB, Dzul S, Abdul Razak HAB, Ahmad Shah Azizi NAB, Kamarudin MB, et al. Importance of proactive malaria case surveillance and management in Malaysia. Am J Trop Med Hyg. 2018;98:1709-13.

30. Mahdy M, Chan B, Noor Hayati M, Sa'iah H, Ismail M, Jeffery JJTB. The distribution of malaria parasites among Orang Asli populations living in the interior areas of Pahang and Kelantan, Malaysia. Trop Biomed. 2004;21:101-5.

31. Jiram Al, Hisam S, Reuben H, Husin SZ, Roslan A, Wan Ismail WR. Submicroscopic evidence of the simian malaria parasite, $P$. knowlesi, in orang asli community. Southeast Asian J Trop Med Public Health. 2016;47:591-9.

32. Kardooni R, Kari F, Yahaya S, Yusup S. Traditional knowledge of Orang Asli on forests in Peninsular Malaysia. Indian J Tradit Know. 2014;13:283-91.

33. Kamal SF, Lim V-C. Forest reserve as an inclusive or exclusive space? Engaging orang asli as stakeholder in protected area management. J Trop For Sci. 2019;31:278-85.

34. Samsurijan MS, Rahman NNNA, Ishak MIS, Masron TA, Kadir OA. Land use change in Kelantan: review of the environmental impact assessment (EIA) reports. Geografia Malays J Soc Space. 2018;14:322-31.

35. Warren M, Cheong WH, Fredericks HK, Coatney GR. Cycles of jungle malaria in West Malaysia. Am J Trop Med Hyg. 1970;19:383-93.

36. Solomon T, Loha E, Deressa W, Gari T, Lindtjorn B. Spatiotemporal clustering of malaria in southem-central Ethiopia: a community-based cohort study. PLoS One. 2019;14:e0222986.

37. Samsuddin NAC, Khan MF, Maulud KNA, Hamid AH, Munna FT, Rahim MAA, et al. Local and transboundary factors' impacts on trace gases and aerosol during haze episode in 2015 El Nino in Malaysia. Sci Total Environ. 2018;630:1502-14.

38. Miyamoto M, Mamat MP, Zakaria NA, Michinaka T. Proximate and underlying causes of forest cover change in Peninsular Malaysia. Forest Policy Econ. 2014;44:18-25.

39. Guerra CA, Snow RW, Hay SI. A global assessment of closed forests, deforestation and malaria risk. Ann Trop Med Parasitol. 2006;100:189-204.

40. Vythilingam I, Wong ML, Wan-Yussof WS. Current status of Plasmodium knowlesi vectors: a public health concern? Parasitology. 2018;145:3240.

41. William T, Jelip J, Menon J, Anderios F, Mohammad R, Awang Mohammad TA, et al. Changing epidemiology of malaria in Sabah, Malaysia: increasing incidence of Plasmodium knowlesi. Malar J. 2014;13:390.

42. Fornace KM, Herman LS, Abidin TR, Chua TH, Daim S, Lorenzo PJ, et al. Exposure and infection to Plasmodium knowlesi in case study communities in Northern Sabah, Malaysia and Palawan, The Philippines. PLoS Negl Trop Dis. 2018;12 6:e0006432.

43. Huestis DL, Dao A, Diallo M, Sanogo ZL, Samake D, Yaro AS, et al. Windborne long-distance migration of malaria mosquitoes in the Sahel. Nature. 2019;574:404-8.

44. Dao A, Yaro AS, Diallo M, Timbine S, Huestis DL, Kassogue Y, et al. Signatures of aestivation and migration in Sahelian malaria mosquito populations. Nature. 2014;516:387-90.

\section{Figures}




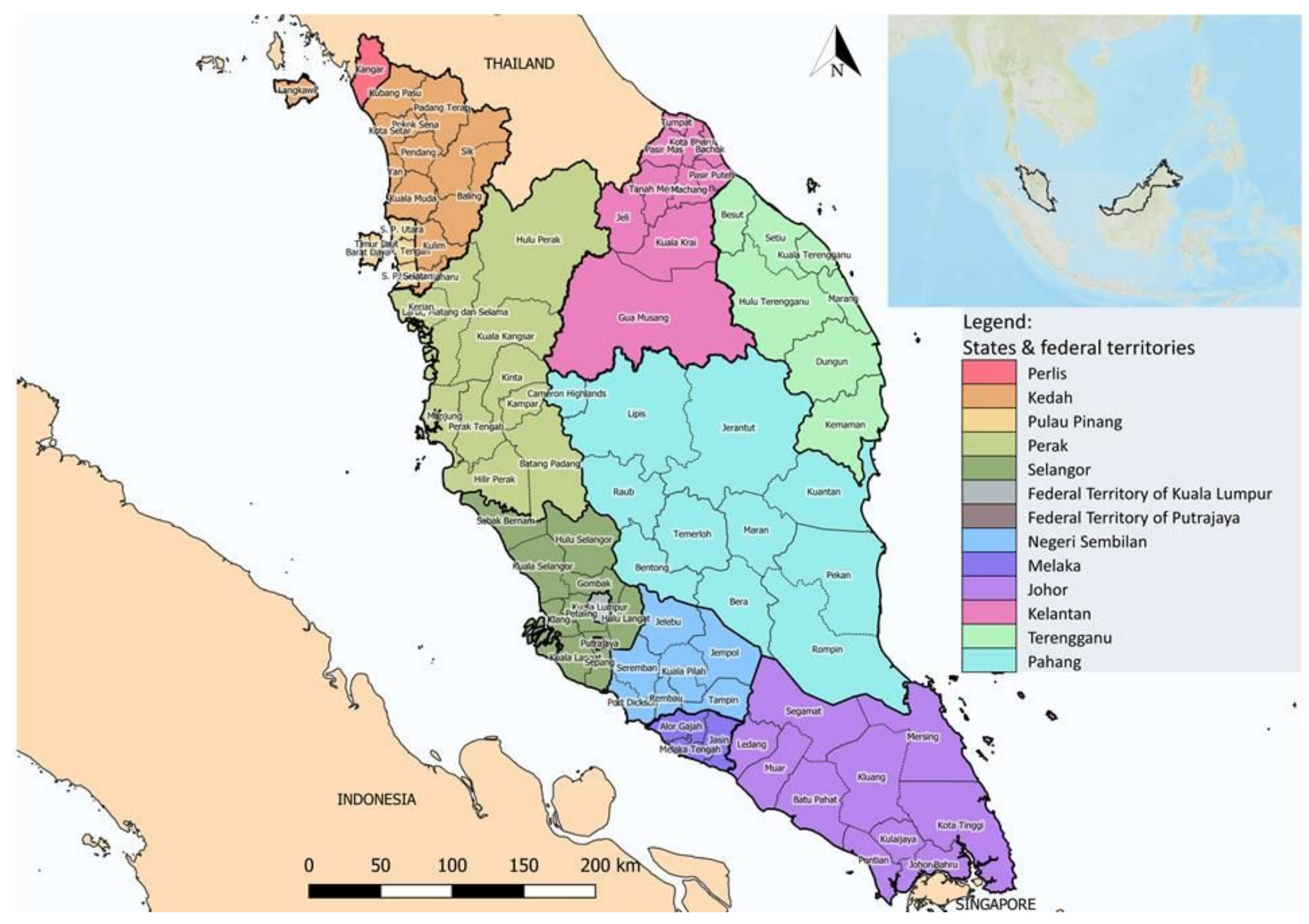

Figure 1

Peninsular Malaysia map showing states and federal territories. Each state is divided into administrative levels of district which are labeled accordingly 


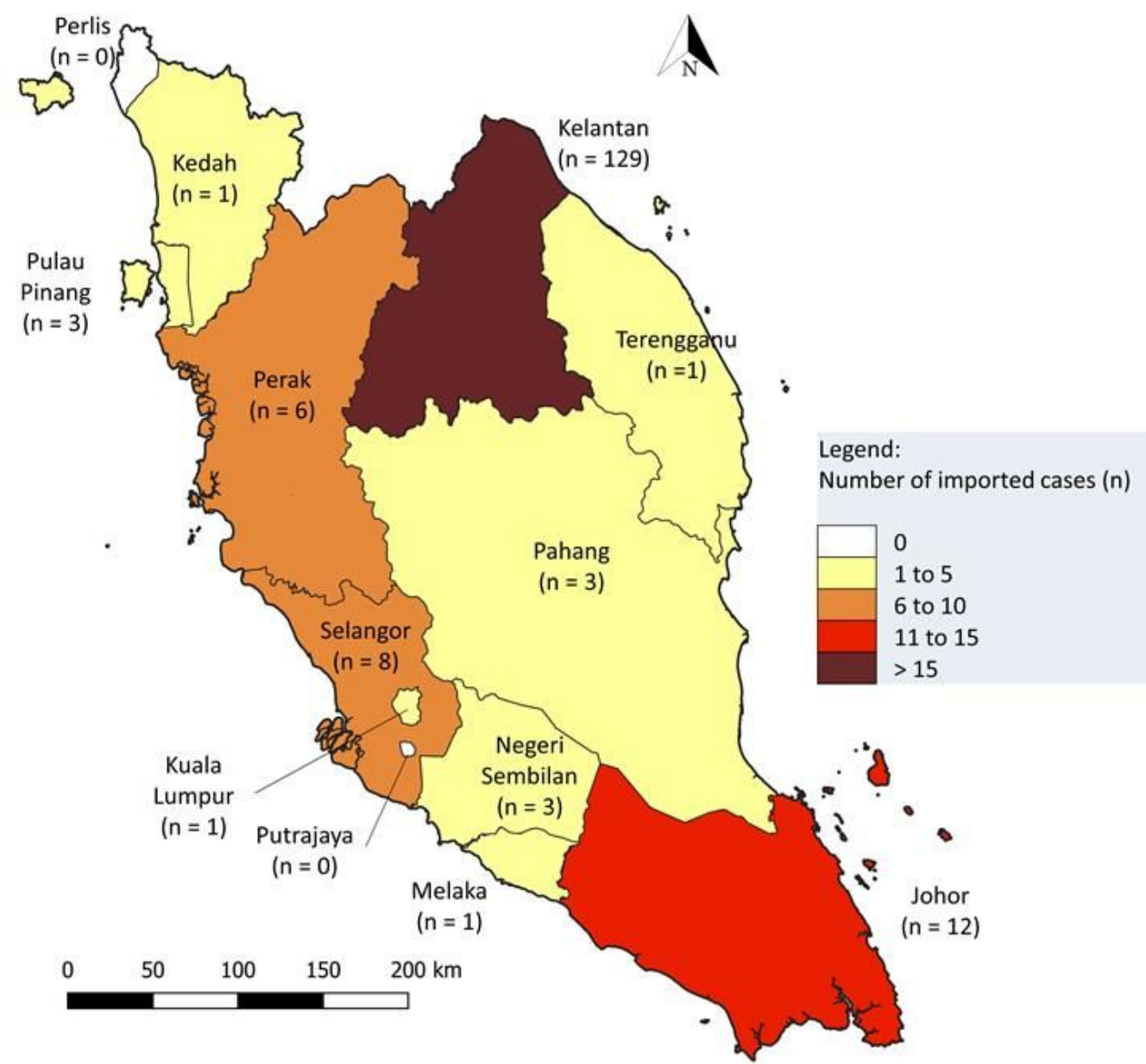

Figure 2

Statewide number of imported knowlesi malaria cases from 2011 to 2018.

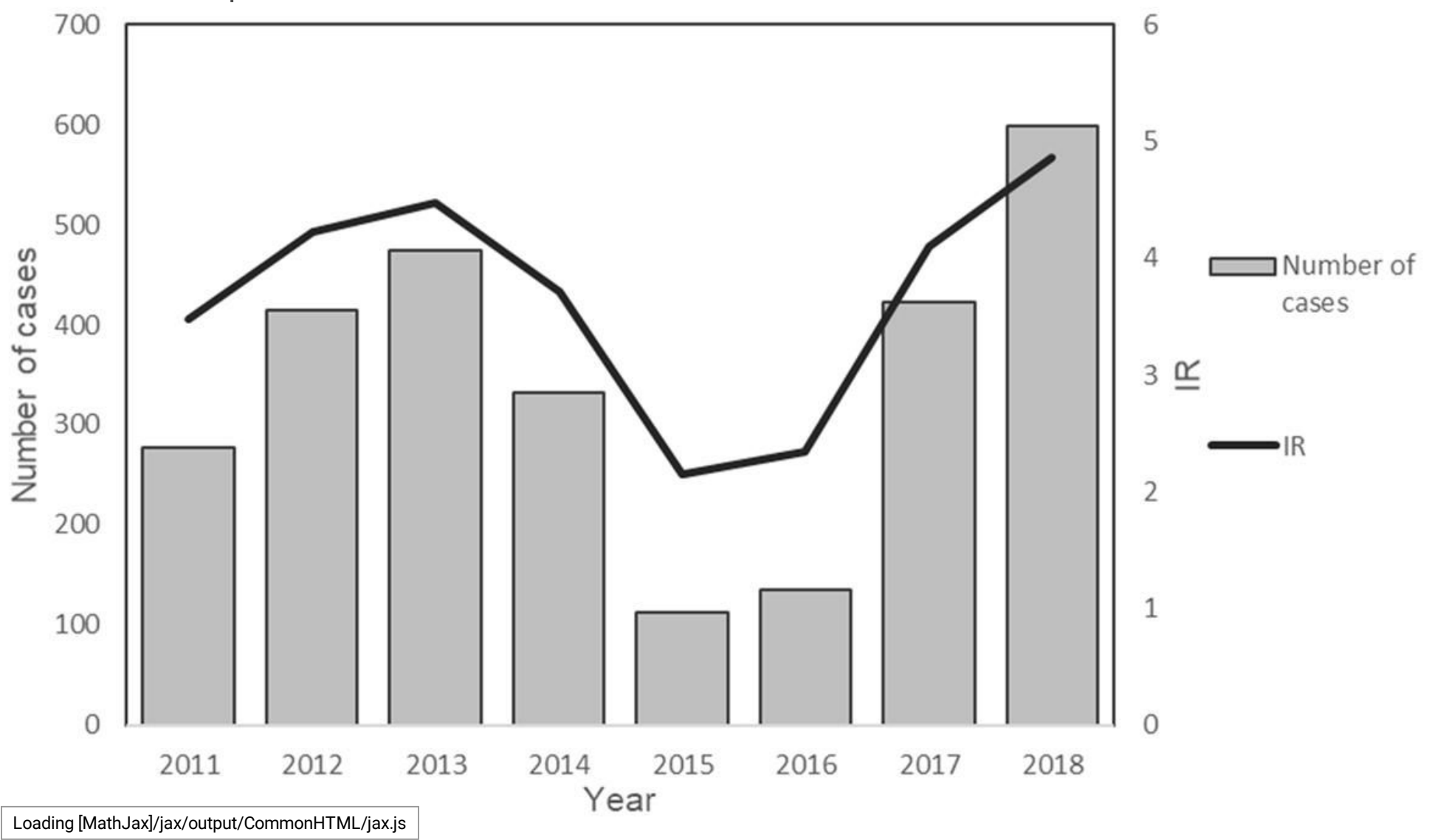


Figure 3

P. knowlesi monoinfection cases in Peninsular Malaysia from 2011 to 2018.

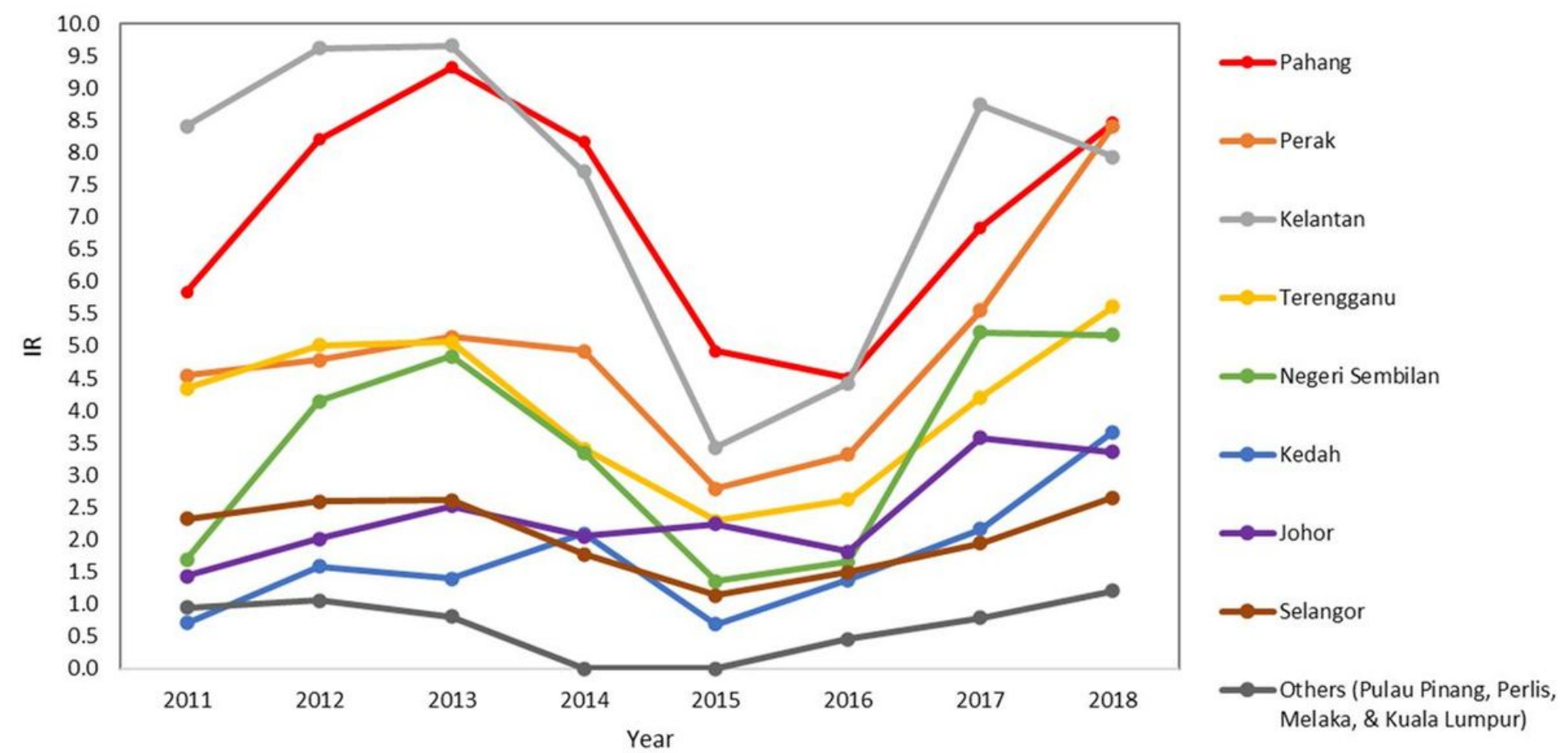

Figure 4

P. knowlesi IR by state from 2011 to 2018.
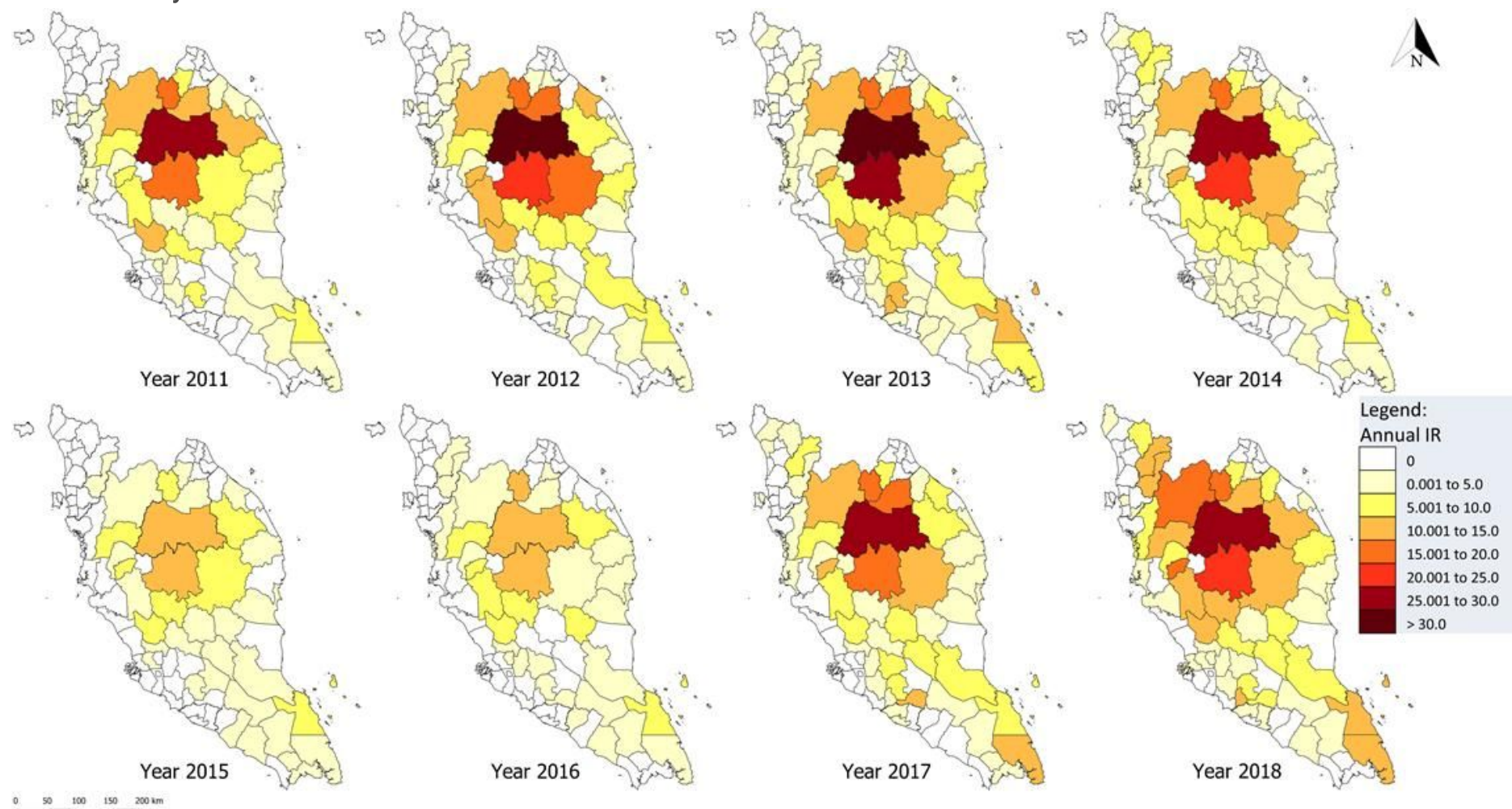

Figure 5

Snatial-temnoral distrihution of knnwlesi malaria in Peninsular Malaysia, 2011-2018. 




Figure 6

Statiscally significant $(P<0.05)$ district-level hotspot and cold spot spatial clusters of knowlesi malaria, 2011-2018.

\section{Supplementary Files}

This is a list of supplementary files associated with this preprint. Click to download.

- supplement1.pdf

- supplement2.tif

- Graphicalabstract.TIF 